\title{
BARRIGA DE ALUGUEL E CONFLITO DE LEIS NO ESPAÇO: CASAIS BRASILEIROS E MÃE DE ALUGUEL NO CONTEXTO DOS BRICS
}

\section{SURROGACY AND CONFLICT OF LAWS: BRAZILIAN COUPLES AND SURROGATE MOTHER IN THE CONTEXT OF BRICS}

\author{
${ }^{1}$ Sylvio Loreto \\ ${ }^{2}$ Arlindo Eduardo de Lima Júnior
}

\section{RESUMO}

Este trabalho analisará o planejamento familiar quando há problema de infertilidade por meio de mãe substituta para superar a limitação biológica. Entre os países do grupo BRICS, pode-se verificar a diversidade na regulamentação do tema que torna viável a reflexão sobre pontos importantes, como soberania, ordem jurídica estrangeira e o interesse público. Assinalar os caminhos para casais pode viabilizar seus planejamentos familiares além das fronteiras nacionais, além de apresentar ao Poder Público a possibilidade de franquear, a estes mesmos casais, alternativas para que enfrentem a dificuldade sob a jurisdição brasileira em razão do estabelecimento de regulamentação jurídica.

Palavras-chave: BRICS; Barriga de aluguel; Planejamento familiar

\begin{abstract}
The aim of this paper is to analyze the familiar planning after a problem caused by infertility and when a surrogate mother is required to substitute the biological one. Among the countries of BRICS the quantity and variety of rules about the question brings opportunity to discuss sovereignty, foreign juridical order and public concern. Indicating solutions couples can have the familiar planning beyond national borders as well as the State (in juridical instances) can give to those couple juridical alternatives and solutions in order to face the difficulties of the Brazilian jurisdiction resulting from juridical rules stablished.
\end{abstract}

Keywords: BRICS; Surrogacy; Familial planning

\footnotetext{
1 Professor Doutor do Programa de Pós-Graduação em Direito da Universidade Federal de Pernambuco UFPE, Pernambuco, PE, (Brasil). E-mail:

2 Doutorando do Curso de Pós-Graduação em Direito da Universidade Federal de Pernambuco - UFPE, Pernambuco, PE, (Brasil). E-mail: edu.dir.est@ hotmail.com.
} 


\section{INTRODUÇÃO}

A intenção deste trabalho é possibilitar uma reflexão a respeito das consequências jurídicas de decisões provenientes das necessidades de casais encontram dificuldades para gestacionar uma criança, bem como das mulheres que podem atuar como mães substitutas a fim de proporcionar a efetivação do direito alheio ao planejamento familiar sem ter seus direitos constitucionais vulnerabilizados em razão da falta de regulamentação ou da existência de um modelo que seja hostil à gestação por mãe substituta fora do seio da família do casal em necessidade, tendo em vista que o modelo que limita é o mais propenso a gerar a exploração ilegal das mulheres.

A análise partirá do planejamento familiar no Brasil, tentando verificar quais as limites legais impostos aos casais que anseiam por ter filhos que representem sua descendência biológica total, no caso de casais heterossexuais ou parcial quando homossexuais. Também, tentar-se-á verificar que efeitos o modelo jurídico nacional pode limitar o exercício ao direito ao livre planejamento familiar a fim de que se possa investigar a existência de possibilidade de utilização de outro marco jurídico que seja mais harmonizado ao exercício de tal direito.

Tendo sido observados que direitos deveriam ser franqueados à família com dificuldade no processo reprodutivo, interessante passar a observar a personagem principal, mas nem sempre vista assim pelo direito posto,que é a mãe substituta, aquela que terá o encargo de tornar realidade o planejamento familiar alheio. Saber se o melhor é restringir as possibilidades ao casal com dificuldade ou ampliar os direitos da mulher a dispor de seu próprio corpo, parece estar articulado nesta modalidade de processo reprodutivo, de maneira que se vislumbra poder trazer ao texto a questão não só do direito do casal, mas também do direito da mulher.

Tomando por base a ordem jurídica brasileira, que é bastante restritiva sobre o tema, debruçar-se-á sobre os países no âmbito do BRICS, tendo em vista a diversidade quanto ao tratamento jurídico dispensado ao tema, que vai da vedação na China, passando pela possibilidade de realização no seio da família no Brasil e a possibilidade de remuneração na Rússia. Isto a fim de observar que modelo harmonizaria os interesses de casais com limitações reprodutivas e mulheres que poderiam viabilizar seus planejamentos reprodutivos. A intenção é refletir sobre a possibilidade de dinamização 
da atuação estatal no sentido de ampliar os direitos fundamentais já expressos na Constituição Federal.

Enquanto as regras nacionais podem oferecer alguma limitação para algumas famílias que não disponham de mulheres que possam levar a termo uma maternidade por substituição, possível será observar que, por meio das regras de direito internacional privado brasileiro, tais limitações podem ser superadas, ainda mais observando que em sede de homologação de sentença estrangeira o mérito não tende a ser reapreciado.

Ainda assim, a busca por uma barriga de aluguel no exterior demandaria um cuidadoso exame de maneira a que o processo fosse conduzido adequadamente preservando a viabilidade de reconhecimento do registro perante a ordem jurídica nacional. Para isso importante observar a questão sob a perspectiva do Direito Internacional Privado brasileiro.

Será por meio do método dedutivo, utilizando a revisão bibliográfica e a observação de caso concreto, propõe-se a condução desta pesquisa. Imagina-se que observar um caso concreto semelhante ao que enfrentaria um casal brasileiro retornando ao país com seu filho pode ser produtivo para que se evitem afrontas à soberania alheia, bem como ofender direitos constitucionalmente protegidos do casal e da mulher, ao mesmo tempo.

Traçado o caminho, justificada a escolha do grupo a ser analisado e indicado o método, interessante passar ao texto.

\section{O DIREITO AO PLANEJAMENTO FAMILIAR NO DIREITO BRASILEIRO: as possibilidades de produção de filiação biológica}

Ao pensar em família, nada mais natural imaginar como parte inerente o desejo de reprodução. Todavia, também é fato que nem todos os casais podem concretizar sozinhos seus direitos à realização de seu planejamento, como previsto na Constituição Federal:

\footnotetext{
Art. 226. A família, base da sociedade, tem especial proteção do Estado. $\S 7^{\circ}$ Fundado nos princípios da dignidade da pessoa humana e da paternidade responsável, o planejamento familiar é livre decisão do casal, competindo ao Estado propiciar recursos educacionais e científicos para o exercício desse direito, vedada qualquer forma coercitiva por parte de instituicões oficiais ou privadas. (grifos nossos).
} 
Uma questão passível de reflexão diz respeito ao significado do trecho livre decisão do casal, tendo em vista que as possibilidades franqueadas não abrangem a possibilidade de inexistir mulheres na família que possam viabilizar uma gestação por substituição. Daí a importância de estabelecer um marco jurídico que garanta o livre exercício do direito de planejamento alinhado ao direito da mulher à liberdade e dignidade.

Sabe-se que é possível superar os obstáculos por meio da adoção, esta sem vínculo genético, e a gestação por substituição, esta tendo um fator que atrai os parentes com dificuldade em reproduzir, consistente na possibilidade de concepção de filho com vinculação genética.

No desejo de ter prole com vínculo genético é que muitos casais buscam a gestação por substituição, porém no Brasil as possibilidades são muito restritas em razão de só ser possível em modalidade gratuita e feita por pessoas com vínculo familiar, que traz vários direitos ao casal, sem, no entanto, franquear à mulher, protagonista do processo, possibilidade ampla de exercício da autonomia da vontade no tocante à disposição do próprio útero. Ainda assim, vale a pena apresentar o que consta na Resolução CFM 2.121/2015 de 24 de setembro de 2015, norma que disciplina o tema, como se pode verificar:

1- As doadoras temporárias do útero devem pertencer à família de um dos parceiros em parentesco consanguíneo até o quarto grau (primeiro grau mãe; segundo grau - irmã/avó; terceiro grau - tia; quarto grau - prima). Demais casos estão sujeitos à autorização do Conselho Regional de Medicina.

2- A doação temporária do útero não poderá ter caráter lucrativo ou comercial.

3- Nas clínicas de reprodução assistida, os seguintes documentos e observações deverão constar no prontuário do paciente:

3.1. Termo de consentimento livre e esclarecido informado assinado pelos pacientes e pela doadora temporária do útero, contemplando aspectos biopsicossociais e riscos envolvidos no ciclo gravídico-puerperal, bem como aspectos legais da filiação;

3.2. Relatório médico com o perfil psicológico, atestando adequação clínica e emocional de todos os envolvidos;

3.3. Termo de Compromisso entre os pacientes e a doadora temporária do útero (que receberá o embrião em seu útero), estabelecendo claramente a questão da filiação da criança;

3.4. Garantia, por parte dos pacientes contratantes de serviços de RA, de tratamento e acompanhamento médico, inclusive por equipes multidisciplinares, se necessário, à mãe que doará temporariamente o útero, até o puerpério;

3.5. Garantia do registro civil da criança pelos pacientes (pais genéticos), devendo esta documentação ser providenciada durante a gravidez;

3.6. Aprovação do cônjuge ou companheiro, apresentada por escrito, se a doadora temporária do útero for casada ou viver em união estável. 
Estas regras são semelhantes às de outras ordens jurídicas e traz em seu bojo comando expresso vedando a modalidade remunerada. Esta vedação, em razão das restrições que impõem a casais nos quais as mulheres sejam inférteis (plural em razão da inclusão dos casais homoafetivos femininos ou heterossexuais), bem como casais homoafetivos masculinos, tendem a impulsionar estes a tentar efetivar seus direitos constitucionais em outra ordem jurídica. Importando considerar que outras ordens jurídicas viabilizam a gestação por substituição por mulheres sem vínculos familiares, incluindo aqueles que albergam a possibilidade do feto não possuir vinculação genética ao casal. Tais peculiaridades deveriam despertar nos estudiosos do direito a necessidade de estudar com maior acuidade o fenômeno de maneira a se buscar a realização no plano interno por meio do franqueamento da possibilidade remunerada, ainda mais quando em sede de reconhecimento de sentença estrangeira ou de registros provenientes do exterior a tendência é que estes filhos terminem sendo reconhecidos da mesma forma, o que não eliminaria a gestação por substituição remunerada.

Como se verá adiante, em sede de um possível pedido de reconhecimento de sentença estrangeira onde houve gestação por substituição remunerada e com vínculo genético com, pelo menos, um dos parentes, o Poder Judiciário Brasileiro não adentraria ao mérito, o que importa na constatação de que o ordenamento jurídico pátrio não repudia os vínculos familiares constituídos desta forma em outro país em razão de problemas ligados à Soberania, não se vislumbrando que óbices impedem a regulamentação feita internamente em benefício dos casais e das mães substitutas.

Um ponto de grande relevância é saber a situação jurídica do filho gerado em gestação por substituição sob outra jurisdição soberana e seu impacto na ordem jurídica brasileira. Como se verá adiante há países que além de atribuir a paternidade ao casal contratante do serviço de surrogacy, no registro não há qualquer menção à mãe substituta, o que levaria a questão que envolveria o seguinte comando constitucional:

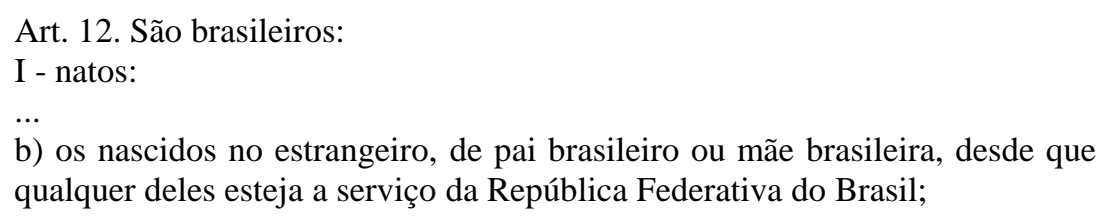

Considerando que na Sentença Estrangeira No 4.525 - US (2009/0077159-0), o STJ tendo plena ciência do método utilizado para a geração do novo ser, reconhecera a 
sentença estrangeira, parece razoável concluir que nas ordens jurídicas que expressamente permitam o surrogacy remunerado, não haverá problemas em trazer as crianças para o país. Todavia grande cuidado deve-se ter com as ordens jurídicas nas quais o tema seja instituto jurídico desconhecido, tendo em vista que o resultado pode ser o descrito em um dos próximos itens.

\section{AS MÃES SUBSTITUTAS: as ordens jurídicas conservadoras e a vulnerabilização da mulher}

A abordagem deste ponto serve para observar como a falta de disciplinamento jurídico adequado pode gerar a exploração ilegal de mulheres.

A análise de um caso concreto ocorrido na Índia, em momento no qual o Estado não estava atento à existência do turismo reprodutivo, possibilitou a criação de uma rede transfronteiriça que via nas mulheres, em vulnerabilidade, uma possibilidade para seu empreendimento de reprodução assistida.

As clínicas de reprodução assistida na Índia desenvolveram-se em respostas às barreiras existentes em países desenvolvidos. Em razão dos custos mais baixos, casais com problemas de fertilidades passaram a procurar o país como destino para a reprodução por substituição comercial (remunerada). A falta de regulamentação estatal e a grande disponibilidade de mulheres dispostas a servirem como mães de substituição, permitiu o rápido desenvolvimento da atividade. Todavia, havia a preocupação sobre o tratamento dispensado às mulheres, que eram vistas como objeto neste nicho, ainda mais considerando que as mulheres eram de classes mais vulneráveis. Naquele momento, o ministério da saúde passou a exigir idade mínima, contratos específicos, o consentimento expresso e solução para questões de adoção (POINTS: 2009, 3). Vale lembrar que atualmente a ordem jurídica indiana passou a vedar tal modalidade de reprodução por substituição e que está a permitir em moldes semelhantes ao já adotado no Brasil.

No trecho no qual se aborda a questão da mãe por substituição ser como uma fábrica há que se observar que não haver nenhum interesse por saber sobre o entendimento da mulher envolvida na questão. A mesma objetificação feita pelos contratantes, é a realizada por aqueles que alegam pretender lha defender. Quanto a este ponto, melhor opção seria saber da disponibilidade da mulher em poder disponibilizar 
seu útero ao planejamento familiar alheio seja a título gratuito, seja a oneroso. Parece descabido aceitar que terceiro possa interferir na autonomia da vontade da mulher sobre a disposição de seu próprio corpo, ainda mais quando manejado a fim de garantir a realização de projeto familiar de quem tem dificuldades, o que nos traria à mente a ideia de solidariedade social, ainda que realizado de forma onerosa.

Da mesma maneira o trecho traz de forma expressa a necessidade, caso seja viabilizada a modalidade, de maior rigidez quanto à idade, direitos da mãe por substituição, direito contratual, a questão do consentimento, entre outros. Acredita-se que a melhor opção seja, ao invés de limitar as possibilidades dos casais que podem não ter entre seus familiares mulheres que cedam seus úteros, ampliar os direitos de disposição do próprio corpo às mulheres, o que nitidamente seria constitucionalmente viável. A ilicitude que reveste a questão hodiernamente no Brasil só tende a gerar um processo paralelo no qual a barriga de aluguel ocorre, mas deixando a mulher bastante vulnerabilizada e despida de qualquer possibilidade de proteção de sua dignidade.

Com relação ao direito de disposição do próprio corpo por parte das mulheres, não pretendendo ser prolixo, apresentar-se-á como é tratada a mulher neste processo de reprodução por útero de substituição.

No Direito Russo os direitos que ainda provocam fortes embates nas sociedades de várias nações pelo mundo, inclusive no Brasil, já dispõe de tratamento mais adequado à ampliação do direito das mulheres como o aborto e a gestação por útero de substituição. Este último caso é o que desperta interesse para este breve estudo.

A título ilustrativo, a leitura de treco do PL 4892/2012 com trâmite na Câmara dos Deputados, há que se observar as limitações impostas ao procedimento, nestes termos:

Art. 23. A cessionária deverá pertencer à família dos cônjuges ou companheiros, em um parentesco até $2^{\circ}$. Grau.

Parágrafo único. Excepcionalmente e desde que comprovadas a indicação e compatibilidade da receptora, será admitida a gestação por pessoa que não seja parente do casal, após parecer prévio do Conselho Regional de Medicina.

Art. 24. Em todos os casos indicados, a cessão temporária de útero será formalizada por pacto de gestação de substituição, homologado judicialmente antes do início dos procedimentos médicos de implantação.

Parágrafo único. São nulos os pactos de gestação de substituição sem a devida homologação judicial, considerando-se, nesse caso, a mulher que suportou a gravidez como a mãe, para todos os efeitos legais, da criança que vier a nascer.

Art. 25. A gestação de substituição não poderá ter caráter lucrativo ou comercial. 
Verificando a rigidez, inclusive com exigência de autorização judicial para a formalização do pacto de gestação de substituição, não haveria nenhum motivo para que se exigisse a vinculação familiar ou impedir o caráter oneroso, tendo em vista que o próprio Poder Público conduziria toda a parte jurídica do processo. Ademais, há que se ponderar tendo em vista que o próprio Poder Judiciário homologa sentenças nas quais a gestação de substituição era desprovida de vinculação familiar entre parentes e mãe substituta, bem como de gratuidade.

Retornando ao Direito Russo, este autoriza a gestação por substituição, mesmo a onerosa, impondo tratamento jurídico mais claro e favorável à proteção da mulher que cede o útero de maneira a permitir a realização do planejamento familiar alheio. Todavia, parece interessante pôr luz sobre um ponto que pode gerar vários questionamentos que diz respeito à gestação heteróloga na qual a criança não tem nenhuma ligação genética com os contratantes.

Em um caso ocorrido na Itália, um casal que utilizara os serviços de uma mãe de substituição russa, em razão da falta de vínculo biológico com a criança (requisito não exigido naquela ordem jurídica) terminou sendo processado pelo Estado. Em razão de questão de ordem pública, as autoridades não reconheceram a possibilidade de registro ao infante, indicando que a conduta do casal visava a contornar a aplicação do direito nacional. A criança foi entregue a uma família substituta, passando a ter em seu registro a informação de que seus pais seriam desconhecidos. A questão, em si, não era que o direito italiano não reconheceria a filiação constituída por meio da reprodução por substituição, mas que não reconheceria aquela na qual não existisse o vínculo genético com a criança. Por fim, a criança terminou definitivamente com a família substituta, não sendo possível sua devolução à família originar de forma a não criar um precedente que estaria em desconformidade com o direito nacional (HAUSAMMANN; QUENON, 2014, 5).

A solução do caso parece bastante clara sobre o resultado da falta de ligação genética com, pelo menos, um dos parentes que buscam no exterior a reprodução por útero de substituição. A razão para o comportamento do Poder Público Italiano afigurase evidente: o tráfico de crianças sob o argumento de gestação por substituição significaria grave tentativa de fraude à lei. Para ilustrar o caso, a legislação russa não exige a ligação genética entre os parentes e o filho gerado (SVINTEV: 2010, 893). 
Então relevante chamar a atenção das famílias interessadas para a conveniência em optar por, pelo menos, a ligação genética com um dos parentes. Não basta apenas verificar a questão legal no país onde será realizado o procedimento, é de grande relevância verificar a receptividade por parte dos países para onde serão levadas as crianças, chamando a atenção que o tráfico de pessoas é reconhecida como prática delitiva no Brasil, maior foco deste trabalho.

Este caso, apesar de ser bastante ilustrativo para os parentes em busca de realização de seu planejamento familiar, o caso concreto foi o menos grave, considerando que a criança poderia ter sido repatriada e levada para um lar despreparado para lhe acolher, o que levaria à mãe substituta um grave problema. Em boa parte dos estudos sobre o tema, a mãe substituta parece uma mera hospedeira e sem relevância na relação entre os parentes de intenção e seus rebentos, quando a importância da mulher deveria ser o centro da questão na medida em que a grande maioria dos países reconhece como mãe a mulher que pare, sendo fenômeno recente a possibilidade de reconhecer os pais que contratam (onerosa ou gratuitamente) os préstimos de uma mãe substituta.

A legislação pode trazer algum parâmetro, todavia será fora do direito que se encontrará como a situação é enfrentada diretamente pelos envolvidos, no caso o foco é a mãe substituta. Há casos nos quais, em razão da rejeição pelos pais contratantes, a criança termina tornando-se órfã ficando inclusive sem filiação. Nestes termos, é possível observar que no direito russo as mães, em razão de balizas jurídicas mais claras, terminam vulnerabilizadas (RUSSIA TODAY, 2014).

Não é muito diferente o que se pode visualizar em textos mais técnicos, nos quais é possível constatar que, apesar da existência de uma regra, esta não é completa no sentido de prover à mãe substituta a proteção satisfatória no âmbito do contrato celebrado com os potenciais pais (ARSLANOV; NIZAMIEVA, 2015, 843).

Verifica-se, por estas passagens que, mesmo onde o tema está disciplinado, ainda há uma longa jornada até que se passe a proteger todos os envolvidos no processo de reprodução por meio de gestação por substituição. Neste caso, o mais notável que a menor proteção é deferida à personagem mais importante: a mulher. 
Não se está a afirmar que os contratos, construídos pelas empresas mesmo sem condicionamentos impostos por lei, sejam leoninos, mas que a falta de proteção de índole normativa impõe vulnerabilidade desnecessária à mãe substituta.

\section{O TRATAMENTO JURÍDICO DO TEMA NO ÂMBITO DO BRICS: como o tema tem sido disciplinado no âmbito deste grupo de países}

No âmbito do grupo BRICS, países escolhidos por ter uma série de peculiaridades que viabilizam uma apresentação bastante fecunda do tema, além de constituírem um modelo alternativo de integração de maneira que a harmonização de suas ordens jurídicas parece tender a produzir regras que protejam o direito ao pleno exercício do direito ao planejamento familiar e, ao mesmo tempo, buscar uma proteção à mãe substituta, tendo em vista o modelo que viabiliza uma possibilidade que permite à mulher dispor com maior autonomia de seu corpo, apesar de ainda demandar maior amadurecimento sobre o estabelecimento de balizas mínimas a fim de que as entidades que intermediam a atividade tenham suas atividades melhor condicionadas e as mulheres maior proteção.

No Brasil, África do Sul e Índia (instituto jurídico desconhecido nos dois últimos) a gestação por substituição só pode resultar de celebração gratuita e envolvendo membros da mesma família com obrigações que garantem direitos às mães substitutas, impondo deveres que podem atingir, inclusive, seu marido que deve abdicar de qualquer pretensão relativa ao novo ser. Na China, a possibilidade inexiste legalmente, todavia há ciência de que ocorre em mercado negro o que chama a atenção para as vantagens, sobretudo para as mães substitutas, na regulamentação jurídica por parte do Estado a fim de condicionar o Poder Econômico garantindo melhor inserção às mulheres, principalmente àquelas que buscam o encargo de mãe substituta movida por necessidades financeiras que as colocam em grave vulnerabilidade. Isto leva à conclusão de que mesmo recebendo pela cessão do útero, percebem ínfimos valores, algo que seria plenamente superável acaso houvesse disciplinamento adequado. A questão não é proibir, e sim sob qual modelo será viabilizado o surrogacy envolvendo mulheres fora do seio familiar dos parentes que buscam a realização de seu planejamento familiar.

O modelo russo, por outro lado, permite à mulher que disponha de seu corpo para o surrogacy, porém falha ao não estabelecer balizas mínimas sobre o conteúdo 
contratual que envolve o tema. Não fixa a proteção mínima a ser destinada contratualmente à mãe substituta, de maneira a garantir-lhe uma vida digna enquanto carrega em seu ventre toda expectativa de realização do planejamento familiar alheio, mas permite a percepção de remuneração e limitando algumas cláusulas leoninas para a mãe substituta.

Verifica-se que, diversamente de outras ordens jurídicas, o direito russo permite a reprodução por substituição remunerada, incluindo o pós-parto, Trata-se de contrato sob a responsabilidade financeira toda para os potenciais pais. Já à mãe substituta não há a obrigação de entregar a criança. Da mesma forma, esta pode vir a realizar aborto (SVITNEV, 2010, 894).

Se mesmo com algum tratamento jurídico favorável à mulher, reclama-se de falta de melhor regulamentação. É importante refletir sobre os efeitos da postura do Estado que trata como ato ilícito o que, além de não impedir a ocorrência do fato, impõe a mulher uma vulnerabilidade que seria dever do Poder Público evitar sua ocorrência por meio do reconhecimento e estabelecimento de rígidas balizas legais a fim de limitar a atuação dos intermediários.

\section{O DIREITO INTERNACIONAL PRIVADO BRASILEIRO E O RESULTADO DE UMA CONTRATAÇÃO DE BARRIGA DE ALUGUEL: reflexões com base em caso concreto ocorrido na Índia}

Não sendo a intenção apresentar, em profundidade, o direito internacional privado, interessante tentar realizar tal intento de forma adequada.

No mundo atual, que é globalizado, não há como não reconhecer que relações jurídicas podem vir a transpor as fronteiras dos Estados Soberanos. Da mesma forma, as questões surgidas destes enlaces podem vir a demandar provimento com base nas ordens jurídicas envolvidas. Vale lembrar que o trabalho dedica atenção à possibilidade de realização do planejamento familiar, no âmbito do direito constitucional brasileiro, por meio da utilização de reprodução de substituição com mãe domiciliada em ordem jurídica que permita a modalidade remunerada, no caso dos BRICS seria o caso do ordenamento jurídico russo.

A diversidade de ordens jurídicas inviabiliza a construção de uma solução que contemple somente ordem jurídica interna de um país, ou de outro, ainda mais quando 
se há de reconhecer ordem jurídica estrangeira. Aqui é onde se pode verificar que a solução dada é por meio de um direito com regras peculiares debruçadas a estas relações privadas com conexão internacional (RECHSTEINER: 2013, 26).

Estas regras, mesmo não resolvendo o caso concreto, dispõe sobre que direito será aplicável a determinada situação optando pelo direito nacional ou estrangeiro sem, todavia, resolver o mérito (RECHSTEINER: 2013, 27). Ressalta-se que tal ramo jurídico, a despeito da denominação, é direito interno quando observada a sua origem, assim é necessário atentar para o fato de que cada país terá suas regras para solucionar conflitos de leis no espaço (RECHSTEINER: 2013, 30).

A solução dos problemas envolvendo pessoas sob ordens jurídicas diferentes são alcançadas por meio da incidência de normas indicativas ou indiretas de direito internacional privado, que são compostas pelo objeto de conexão e elemento de conexão. Enquanto o objeto de conexão descreve a matéria à qual se refere a norma de direito internacional privado, aludindo a conceitos jurídicos, como a capacidade jurídica, nome de pessoa natural, o elemento de conexão é torna possível a determinação do direito aplicável e pode ser a nacionalidade, domicílio e residência habitual. (RECHSTEINER: 2013, 162-163).

No caso brasileiro, o direito internacional privado prevê que o direito aplicável às obrigações contratuais será o do lugar de sua constituição, sendo este o da residência do proponente (RECHSTEINER: 2013, 164).

Tendo sido a relação jurídica voltada à reprodução por substituição contratada e realizada sob ordem jurídica estrangeira, poderia um juiz, aplicando o direito brasileiro, desconstituir a relação parental com vinculação genética, sob o argumento de ofensa à ordem pública ou fraude à lei? Como se verá adiante, em sede de homologação de sentença estrangeira, o STJ não adentra ao mérito, o que importa em concluir que a relação não seria afetada pelo direito interno.

Feita esta abordagem propedêutica, delineando o direito internacional privado, ramo do direito que pode ser a solução para a realização do planejamento familiar de casais com problemas de fertilidade, interessante voltar ao exemplo indiano a fim de tentar observar o melhor caminho para um casal brasileiro afetado por esta limitação.

Observando a situação ocorrida na Índia, país onde a contratação de barriga de aluguel era possível e que pareceria, de antemão, uma opção interessante para a 
realização de projetos de ampliação da família por parte de casais com problema de fertilidade ou de inviabilidade por limitação de ordem biológica.

À época do caso apresentado, não havia por parte do Poder Público Indiano nenhuma regra ou postura do Estado sobre o tema, o que viabilizou o surgimento de um nicho no campo da reprodução assistida, como já apresentado anteriormente.

Observa-se, neste caso concreto, que foi a falta de regulamentação que criou uma rede transfronteiriça de reprodução assistida que necessitava de mulheres para a realização de seu projeto de negócio. Eis a importância da regulamentação por parte do governo no sentido não de proibir, mas de garantir que esta contratação ocorra sob condições bastante rígidas e controladas e com ampla garantia de direito às mulheres envolvidas no projeto de planejamento familiar alheio.

A falta de disciplinamento jurídico para o caso terminou por levar ao casal problemas de ordem legal, na medida em que o país para onde a criança retornaria seria o Japão onde mãe é a mulher que pare, algo não muito diferente do Brasil.

Conhecer a ordem jurídica na qual se busca a realização do desejo de aumentar a família é questão de bastante relevância quando se deseja evitar infortúnios. O fato de não haver regulamentação sobre o tema na Índia, além de não significar autorização não evitou o surgimento de barreiras em razão de outras normas, como a que vedava a homens a adoção de meninas.

Não tendo sido viável ao casal japonês obter o registro de seu filho por meio de gestação por substituição na Índia, ante os obstáculos de índole legal, interessante apresentar como foi contornado tal impasse. A expectativa é sinalizar aos casais que existem países onde o procedimento é reconhecido legalmente o que leva maior proteção à mulher, além de garantias maiores de sucesso em seu intento.

No caso do bebê Manji a solução foi seu registro na Índia e a posterior expedição de passaporte humanitário japonês, o certificado expedido na Índia não fazia menção à nacionalidade. O governo japonês acenou para a possibilidade de concessão de nacionalidade tão logo fosse estabelecida a relação parental, com o pai reconhecendo sua paternidade e a adotando. Porém, a pesquisa terminou sem que a condição do bebê tivesse sido definitivamente resolvida (POINTS: 2009, 6 - 7).

O resultado foi registro da criança na Índia e a concessão, por parte do Governo do Japão, de visto humanitário, até que em algum momento a criança pudesse ser 
adotada por sua família, incluindo seu pai biológico. A medida colocou a criança em grande situação de vulnerabilidade até que os pais pudessem contornar os óbices legais a fim de estabilizar a situação jurídica de seu infante. Importante chamar a atenção para o problema a fim de que as famílias tenham plena consciência de que a realização de gestação por substituição em países por um critério predominantemente financeiro pode gerar efeitos deletérios à efetivação do planejamento familiar.

Caso ilustrativo, assinala-se que na Índia está em trâmite Projeto de Lei que restringe a gestação por substituição para um modelo muito semelhante ao brasileiro no qual a gestação será por meio de mulher da própria família e gratuito. Nos termos até então apresentados, será vedado o modelo comercial de gestação por substituição, bem como seu acesso a estrangeiros. Se onde o disciplinamento jurídico existe, a mãe substituta já não goza de proteção adequada, pior será onde a proteção legal não existe.

Para os casais que, por falta de opção no Brasil, necessitem buscar a satisfação de seu planejamento familiar é deveras importante ter ciência sobre a viabilidade de seu projeto a fim de evitar a existência das mesmas dificuldades apresentadas nas linhas precedentes.

Sabe-se que no Brasil é possível a gestação por substituição, todavia a título gratuito e no seio da família do casal, bem como da vedação à realização do projeto por meio de mulher que não seja da família e a título oneroso. Da mesma forma, tem-se conhecimento que em outros países é possível a gestação por mulher não integrante da família. Acresça-se que em alguns, inclusive, isto é feito por contrato no qual a mulher é remunerada e a ela se garante uma série de direitos, o que é consentâneo à ideia de ampla autonomia da vontade e de direitos ao próprio corpo por parte das mulheres.

A questão é saber se estas gestações por substituição importariam em problemas para os casais brasileiros sabendo que no Brasil, para os casos de gestação por substituição, é dispensável a inclusão do nome da gestante na declaração de nascido vivo, conforme a Provimento n. 52, de 14 de março de 2016, bem como no Registro do infante.

Não parece haver dificuldades no Brasil em aceitar a ordem jurídica dos países nos quais a mulher possa por contrato servir como surrogate mothers, bastando observar um precedente de período anterior à criação da Resolução do CNJ:

J. H., brasileiro, e D. L. M., norte-americano, qualificados na inicial, formulam pedido de homologação da sentença estrangeira proferida pelo Juízo Federal do Condado de Cook, Estado de Illinois, E.U.A., 
que, em 6 de janeiro de 2009, concedeu ao segundo requerente a adoção de A. E. H., nascida nos E.U.A. e filha biológica do primeiro requerente.

A menor está sob a custódia dos requerentes, os quais vivem em união homoafetiva, nos Estados Unidos da América, há nove anos.

A concepção da criança foi originada a partir de uma inseminação artificial heteróloga, com a utilização de óvulos doados por uma mulher não identificada, de acordo com as regras norte-americanas, que foram combinados com o material genético de J. H., o qual, por isso, é o pai biológico da menor e detém sobre ela o poder familiar.

Pleiteiam os requerentes a homologação da sentença de adoção, a fim de que conste, no assento de nascimento da menor A. E. H., a condição de ser filha de ambos, sem ser declarada a condição de cada qual como pai ou mãe. (SENTENÇA ESTRANGEIRA No 4.525 - US (2009/0077159-0))

Observando o caso concreto, relevante notar que se trata de questão emblemática no que tange ao reconhecimento dos filhos resultantes de gestações por substituição e nota-se que o desate da questão é pelo reconhecimento da legislação do país onde ocorrera o nascimento do filho, sem nenhuma restrição o que leva à conclusão que não deverá haver dificuldades para famílias brasileiras com problemas de fertilidade em realizar seus desejos de ampliação da família e trazer para o Brasil seus rebentos, desde que observadas as legislações dos países nos quais se busca realizar o projeto, como se pode notar na decisão que homologou a sentença estrangeira. Ainda que observada diretamente, não se constata incursão na questão de mérito que versa sobre a contratação de mãe de substituição para a gestação do bebê. Vale registrar que no caso, há regras expressas nos Estados Unidos que autorizam a realização de gestação por substituição a título oneroso e sem a necessidade de inclusão do nome da surrogate mother no registro da criança.

\section{CONSIDERAÇÕES FINAIS}

Neste breve estudo, feito a partir da perspectiva brasileira, verificou-se que o aluguel temporário do útero é reconhecido na ordem jurídica pátria, bem como nos demais países do grupo BRICS. Todavia o tratamento jurídico varia da proibição, passando pela possibilidade de realização a título gratuito por meio de mãe substituta que tenha vínculos familiares com um dos parentes e alcança a possibilidade de ser realizado de forma onerosa e por mãe substituta sem vínculo com a família. 
Também observa-se que grande atenção é dedicada à família que busca satisfazer um planejamento familiar mesmo que por substituição, todavia sem dar o tratamento jurídico adequado à protagonista do evento: a mãe substituta, a mulher!

Nestes termos, observa-se que franquear a possibilidade de gestação por substituição onerosa não é só uma forma de facilitar a vida dos casais, mas também de ampliar o direito da mulher de dispor do próprio corpo. Considerando que mesmo na modalidade remunerada, poucas pessoas disporiam do próprio corpo para proporcionar a famílias com impossibilidade de geração de filhos biológicos a realização de um sonho, este albergado pela Constituição Federal.

Frise-se que se deve ter ciência que o debate jurídico encaminhado também é afetado por outros fatores, notadamente os de cunho moral e teológico. Nestes termos é de grande importância que sejam construídas soluções para que a reprodução por substituição possa ser desenvolvida (ARSLANOV; NIZAMIEVA, 2015, 843), o que favoreceria a plena satisfação da norma constitucional sobre a liberdade do planejamento familiar.

A experiência de outros países aponta para a necessidade de busca de um padrão normativo que harmonize, separando o direito de outras perspectivas, o interesse justo de casais afetados por problemas ligados à fertilidade aos das mães substitutas. Considerando que estas deveriam poder, em razão do exercício de sua autonomia da vontade, satisfazer esta necessidade das famílias percebendo uma dádiva financeira a fim de compensar o sacrifício realizado.

O entendimento, em sede de Direito Internacional Privado, no Brasil, é de que a tendência é o reconhecimento da gestação de substituição onerosa, na qual haja vinculação genética com os pais contratantes, feita sob outra jurisdição que discipline o tema, valendo a seguinte lição sobre o fundamento jurídico:

\footnotetext{
Apesar de a regra brasileira ser a da celebração (lex loci contractus), a lei da execução, muitas vezes, tem preponderância, pois a interpretação dominante é de que à lei do local da constituição do contrato, somam-se as exigências da norma de sua execução.

O tema referente à lei aplicável em matéria de contratos internacionais não é a única preocupação com relação à autonomia das partes. Também com relação à escolha do juízo competente para julgar a causa há problemas, como se verá da análise da jurisprudência. A regulamentação das hipóteses de competência internacional no Brasil está no Código de Processo Civil, nos artigos 88 a 90, que trata, de forma ampla, das hipóteses de sua ocorrência exclusiva e concorrente. No caso da jurisdição concorrente, onde há a possibilidade de escolha de foro, prevê a lei a possibilidade de que outros países conheçam da mesma lide, não impossibilitando o juiz brasileiro de também conhecê-la. Mas nos casos em que a escolha recaiu sobre a justiça
} 
estrangeira, muitas vezes o juiz nacional não abriu mão da possibilidade de julgar a causa, tornando a cláusula sem efeito (ARAÚJO; JACQUES: 2008, 269).

Considerando que a contratação e a execução acontecerão sob jurisdição que reconheça como lícita a possibilidade, e feito o registro da criança em nome dos pais brasileiros com os quais tem vínculo genético, não se vê motivo para decisão contrária que atentaria contra a jurisdição de outro Estado soberano.

Não é uma questão de transformar a atividade em uma indústria, mas de equalizar interesses a fim de proporcionar ampliação de direitos constitucionais fundamentais como o do planejamento familiar, por parte dos casais, e de liberdade, no caso das mães substitutas.

\section{REFERÊNCIAS}

ARAÚJO, Nádia de; JACQUES, Daniela Corrêa. Contratos internacionais no brasil: posição atual da jurisprudência no Brasil. Revista Trimestral de Direito Civil. V. 34. 267-280. 2008

ARAUJO, N., VARGAS, D., MARTEL, L.C.V. Gestação de Substituição: regramento no direito brasileiro e seus aspectos de direito internacional privado. Direito Internacional Contemporâneo, Curitiba, 2014. Acessado em: http://nadiadearaujo.com/wp-content/uploads/2015/03/GESTA\%C3\%87\%C3\%83ODE-SUBSTITUI\%C3\%87\%C3\%83O-REGRAMENTO-NO-DIREITO-BRASILEIROE-SEUS-ASPECTOS-DE-DIREITO-INTERNACIONAL-PRIVADO.pdf

ARSLANOV, Kamil M.; NIZAMIEVA, Olga N. Surrogacy: Legal and moral dimension on the problem from the perspective of the Russian, Foreign and International experiences. Research Journal of Applied Sciences. 2015. ISSN: 1815932X. Acessado em: http://docsdrive.com/pdfs/medwelljournals/rjasci/2015/841844.pdf

European Parliament. A Comparative Study on the Regime of Surrogacy in EU Member States.

PE 474.403.

Acessado em: 
http://www.europarl.europa.eu/RegData/etudes/etudes/join/2013/474403/IPOL-

JURI_ET(2013)474403_EN.pdf Páginas 333 a 338.

GUIMARÃES, Cláudia Maria Resende Neves. HOMOLOGAÇÃO DE SENTENÇA ESTRANGEIRA: Gestação de substituição transnacional, o caso Mennesson e a Ordem Pública no Brasil. In: Silveira, Vladimir Oliveira; Silva, karine de Souza; Angelin, Rosângela. (Org.). Homologação de sentença estrangeira : gestação de substituição transnacional, o caso Mennesson e a Ordem Pública no brasil. 1ed Florianópolis: Fundação Boiteux, 2014, v. 1. p 304-333.

HAUSAMMANN, Christina; QUENON, Nicole Hitz. Maternité de substitution: la perspective des droits humains Une pratique à juger à l'aune de l'intérêt supérieur et des droits de l'enfant. Newsletter CSDH No 25 du 11 mai 2014 Domaines thématiques Politique genre et Politique de l'enfance et de la jeunesse. Acessado em: http://www.skmr.ch/cms/upload/pdf/150511_maternite_substitution.pdf

POINTS, Kari. Commercial surrogacy and fertility tourism and India: the case of baby Manji. The kenan Institute for Ethics. Acessado em: https://web.duke.edu/kenanethics/casestudies/babymanji.pdf RECHSTEINER, Beat Walter. Direito Internacional Privado: teoria e prática. 16 ed. Ver e atual. São Paulo: Saraiva, 2013

Russian Today. Surrogate mother database. Acessado em: https://www.rt.com/politics/154496-russia-surrogacy-single-bill/ The Law Library of Congress. BIOETHICS LEGISLATION IN SELECTED COUNTRIES. Global Legal Research Center LL File No. 2012-008118. Acessado em: https://www.loc.gov/law/help/bioethics_2012-008118FINAL.pdf

SVITNEV, Konstantin. Legal regulation of assisted reproduction treatment in Russia. Reproductive BioMedicine Online (2010) 20, 892- 894. Acessado em: http://www.rbmojournal.com/article/S1472-6483(10)00174-4/pdf 